\title{
Programa Mais Médicos: em busca de respostas satisfatórias
}

\author{
More Doctors Program: in search of satisfying answers
}

Programa Más Médicos: en busca de respuestas satisfactorias

Mário Scheffer (a)

O artigo em debate, ao apresentar os sistemas de saúde australiano e norteamericano, em contraste com o Brasil, traz um panorama sobre o difícil desafio, compartilhado por diversos países, de enfrentar a má distribuição ou a falta localizada de médicos.

No sentido de ampliar o debate e evidenciar sua complexidade, tomam-se por base duas extensas revisões publicadas ${ }^{1,2}$ que recensearam medidas destinadas a garantir a presença de médicos em áreas desassistidas, em interiores e subúrbios.

Esses estudos sublinham que as respostas não são únicas e nem mesmo duráveis ou satisfatórias.

Alguns fatores-chave, determinantes da escolha, pelo médico, do lugar de seu exercício profissional, têm sistematicamente influenciado a recorrência do problema.

Por exemplo, sabe-se que a ausência de atratividade de regiões com piores indicadores sociais e as condições inadequadas de trabalho, com cargas horárias excessivas e má remuneração, dificultam a fixação de médicos. A renda elevada pode não ser uma compensação quando médicos são submetidos ao isolamento profissional e à baixa qualidade de vida deles próprios e de seus familiares.

Não há que contar com o assistencialismo de base filantrópica individual e pessoal de médicos decididos a cobrirem populações carentes. $O$ altruísmo que caracterizou o início da profissão médica moderna, há muito foi substituído pela ideologia profissional de valorização das ultraespecialidades, dos altos rendimentos pessoais e da transformação dos próprios consultórios em microempresa inserida num competitivo mercado de negócios ${ }^{3}$.

Nesse sentido, um dos apelos possíveis está locado nas políticas públicas e gestões macroeconômicas, que produzem desenvolvimento regional e ajudam a corrigir alguns aspectos geradores da má distribuição de efetivos médicos.

Além dos programas similares ao brasileiro, os sistemas nacionais de saúde têm buscado várias outras soluções ${ }^{1}$, que podem ser agrupadas em três tipos de estratégias, independente do grau de sucesso de cada qual.

O primeiro grupo de medidas tem foco nos futuros médicos, aumentando, desde a graduação, o número e a qualificação dos dispostos a trabalhar nas

(a) Departamento de Medicina Preventiva, Faculdade de Medicina, Universidade de São Paulo. Av. Dr. Arnaldo, 455, $2^{\circ}$ andar, sala 2166, Cerqueira César. São Paulo, SP, Brasil. 01246-903. mscheffer@usp.br 
regiões menos atrativas; o segundo, dirigido aos médicos já em atividade, inclui incentivos financeiros e regulatórios para deslocar os profissionais que vivem concentrados em determinadas regiões e atividades; o terceiro prevê alternativas que envolvam outros profissionais de saúde combinadas com tecnologias de telemedicina e assistência à distância.

As intervenções diversas adotadas por países² tentam agir sobre diferentes momentos do percurso profissional: na formação inicial, no recrutamento ou instalação, na fixação ou manutenção do médico no local do trabalho.

Há limites claros de, pelo menos, três medidas mobilizadas: 1) o aumento do número global de médicos é ineficaz, pois gera saturação da oferta e concorrência exacerbada em áreas onde já existe alta densidade de médicos; 2) os incrementos financeiros são insuficientes, pois tal política tem custo elevado, estimula a permanência provisória e não fixa médicos em médio e longo prazo. Da mesma forma, assistiram impacto relativo, não sustentável, países que promoveram ajuda monetária, bolsas, bônus, condições compensatórias e preferenciais em especializações e residências médicas, como contrapartida à instalação de jovens médicos em regiões deficitárias; 3 ) as políticas de recrutamento de estrangeiros, baseadas na melhor remuneração e no aperfeiçoamento profissional como fatores de atração, ainda que permitam o ajustamento emergencial da oferta em áreas remotas, não podem ser vistas como panaceia, pois a disponibilidade internacional de migração de médicos atingiu um certo limite $^{4}$.

A literatura menciona resultados mais favoráveis às iniciativas que visam modificar a formação inicial, capazes de conduzir os estudantes a se instalarem, posteriormente, nos locais remotos, e de adaptar os conteúdos da graduação à prática em atenção primária à saúde.

No Brasil, a dosagem e a combinação de possíveis medidas devem considerar cenário mais adverso que outros países, pois, em nosso caso, às desigualdades regionais de distribuição de médicos somam-se a cristalização do subfinanciamento do Sistema Único de Saúde e a adoção de políticas que promovem o acirramento da privatização da saúde, subtraindo médicos e serviços, drenando recursos humanos e financeiros do sistema público ${ }^{5}$.

Uma contribuição do artigo em debate é a apresentação dos motivadores e critérios utilizados para a decisão política: de alocação de médicos brasileiros e estrangeiros em municípios selecionados, de expansão da oferta de cursos de medicina e vagas de Residência Médica, e de mudanças curriculares dos cursos de graduação, que são os constituintes do Programa Mais Médicos. O manuscrito resgata iniciativas governamentais já testadas no Brasil desde os anos 1990, todas elas de curto alcance e baixo impacto, para, em seguida, deter-se na descrição do Programa Mais Médicos, considerado, pelos autores, medida mais abrangente "para combater as desigualdades de acesso à atenção básica resolutiva".

Se, talvez, o programa seja mesmo abrangente no sentido da quantidade de médicos alocados - o que poderia ser mais bem qualificado por pesquisas de avaliação que evidenciem o impacto sobre as condições de saúde da população assistida -, pode-se indagar sobre sua durabilidade.

Para que o debate resulte em proposições que aprimorem a política pública, impressões entusiasmadas devem ser ponderadas com possíveis fragilidades.

Ao fixar médicos, por meio de provimento emergencial, o projeto ampliou a assistência na atenção básica em regiões carentes desses profissionais ${ }^{6}$, além de ter possibilitado, aos médicos brasileiros, intercambiarem experiências com médicos estrangeiros ${ }^{7}$. Eis aqui, sem dúvida, aspectos positivos.

Entretanto, foram levantadas inadequações ${ }^{8}$ pontuais: na execução das atividades de supervisão e tutoria, no acolhimento e na capacitação dos profissionais, na decisão de gestores locais em substituir médicos contratados por intercambistas, nas punições a médicos cubanos que mantêm seus familiares no Brasil.

E há também preocupações quanto à sustentabilidade do projeto em si, após os seis anos da prorrogação permitida em lei, considerando o modelo paliativo baseado em bolsas de especialização, com componente assistencial mediante integração ensino-serviço, e sua inexequibilidade de longo prazo, decorrente do formato atual fortemente dependente dos acordos de cooperação entre Brasil e Cuba intermediados pela Organização Pan-Americana da Saúde (OPAS). 
Para pesquisadores que são, eles próprios, responsáveis pela condução e execução de um dado programa analisado, é compreensível a exaltação das positividades e das qualidades diferenciais, em comparação com outras políticas já experimentadas.

Mas estudos e pesquisas são orientados por outra direção: todo pesquisador examina a questão por diversos ângulos e quer, pela crítica ao não alcançado, isto é, pelas negatividades, chegar a melhorias de outras mais positividades.

No caso, para além do adágio "é difícil ser juiz e parte", o posicionamento epistemológico equilibrado do pesquisador em relação ao seu objeto, elucidaria a necessidade de distanciamento ou, mesmo, a explicitação das escolhas de abordagem definidas pela proximidade.

Cabe aos estudos sociais e políticos partirem do apontamento de problemas detectados nas realidades vividas, para alcançarem, pela reflexão crítica, ações mais efetivas.

Nesse sentido, deve-se repensar a abrangência e a magnitude da atual política brasileira de alocação de médicos em regiões vulneráveis.

E se, de fato, a proposta vigente foi célere, talvez essa rapidez corresponda exatamente ao seu caráter emergencial. Caberia, então, ao temporário como solução, cambiar-se em políticas permanentes.

A meta há de ser mesmo 'procurar novos caminhos', conciliando a governabilidade do momento com o desenvolvimento do estado democrático e a promoção do direito universal à saúde. Para os gestores públicos, ser governo e, ao mesmo tempo, homens de estado tem sido um grande desafio contemporâneo.

\section{Referências}

1. Ono T, Schoenstein M, Buchan J. Geographic Imbalances in Doctor Supply and Policy Responses. OECD Health Work Papers. 2014; 69:1-66.

2. Bourgueil $Y$, Mousquès J, Tajahmadi $A$. Comment améliorer la répartition géographique des professionnels de santé?: les enseignements de la littérature internationale et des mesures adoptées en France [Internet] [acesso 2015 Abr 23]. Rapport n 534 (biblio n 1635). Paris: Institut de recherche et documentation en économie de la santé. 2006. Disponível em: http://www.irdes.fr/Publications/Rapports2006/rap1635.pdf

3. Schraiber LB. O médico e seu trabalho: limites da liberdade. São Paulo: Hucitec; 1993.

4. OECD Health Policy Studies. The looming crisis in the health workforce: how can OECD countries respond? [Internet] [acesso 2015 Abr 23]. OECD; 2008. Disponível em: http:// www.who.int/hrh/migration/looming_crisis_health_workforce.pdf

5. Marten R, Mclntyre D, Travassos C, Shishkin S, Longde W, Reddy S, et al. An assessment of progress towards universal health coverage in Brazil, Russia, India, China, and South Africa (BRICS). The Lancet. 2014; 384(9960):2164-71. 
6. Organização Pan-Americana da Saúde. Nota da OPAS/OMS no Brasil sobre o Projeto Mais Médicos [Internet]. 2015 [acesso 2015 Abr 23]. Disponível em: http://www.paho. org/bra/index.php?option=com_content\&view =article\&id=4798: nota-da-opasomsno-brasil-projeto-mais-medicos\&catid=1274:programa-especial-mais-medicosnoticias\&ltemid $=827$

7. Machado MH, Campos F, Lima N. Em defesa do Mais Médicos. Valor Econ. 28 Jan 2015; Opinião.

8. Tribunal de Contas da União. Relatório de Auditoria do Programa Mais Médicos [Internet]. 2015 [acesso 2015 Mar 20]. Disponível em: http://portal2.tcu.gov.br/portal/ page/portal/TCU/imprensa/noticias/noticias_arquivos/005.391-2014-8\%20Mais\% 20 M\% C3\% A9dicos.pdf 